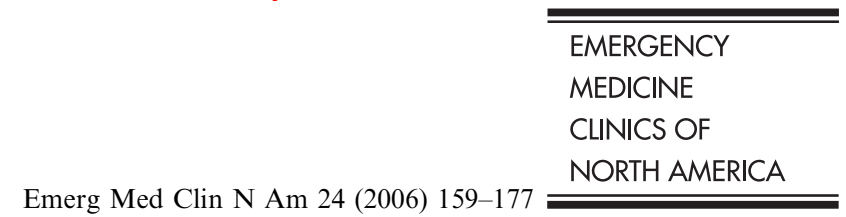

\title{
ECG Manifestations: The Poisoned Patient
}

\author{
Christopher P. Holstege, MD*, David L. Eldridge, MD, \\ Adam K. Rowden, DO \\ Division of Medical Toxicology, Department of Emergency Medicine, \\ University of Virginia, P.O. Box 800774, Charlottesville, VA 22908-0774, USA
}

Emergency physicians routinely evaluate and manage poisoned patients. In 2003, more than 2 million human exposure cases were reported to poison centers throughout the United States [1]. Of those cases, 22\% were treated in a health care facility with most of those cases evaluated in the emergency department. Cardiovascular drugs were listed as the fifteenth most frequently encountered human exposure $(66,401)$ and the fifth leading cause of poisoning deaths.

Drug-induced changes and abnormalities on the 12-lead electrocardiogram (ECG) are common. There are numerous drugs that can cause ECG changes and lead to cardiac dysrhythmias. The diagnoses and subsequent management of patients manifesting ECG changes following poisonings can challenge even the most experienced physician. Drugs that are advocated in Advanced Coronary Life Support protocols for cardiac dysrhythmias may not apply or may even worsen the condition of overdose patients [2].

Despite that drugs have widely varying indications for therapeutic use, many unrelated drugs share a common cardiac pharmacologic effect if taken in overdose. The purpose of this article is to group together agents that cause similar electrocardiographic effects, review their pharmacologic actions, and discuss the electrocardiographic findings reported in the medical literature. The five main categories reviewed include potassium $(\mathrm{K}+)$ efflux blockers, sodium $(\mathrm{Na}+)$ channel blockers, sodium-potassium adenosine-triphosphatase $(\mathrm{Na}+/ \mathrm{K}+$ ATPase) blockers, calcium channel blockers (CCB), and beta-adrenergic blockers (BB). It is important to keep in mind, however, that many medications have actions that involve more than one of these

* Corresponding author.

E-mail address: ch2xf@virginia.edu (C.P. Holstege). 
actions, and thus may result in a combination or myriad of electrocardiographic changes.

\section{Cardiac physiology}

To understand the ECG changes associated with various drugs, physicians must have a clear understanding of basic myocardial cell function. The myocardial cell membrane in its resting state is impermeable to $\mathrm{Na}+$ (Fig. 1). The $\mathrm{Na}+/ \mathrm{K}+$ ATPase actively pumps three sodium ions out of cardiac cells while pumping in two potassium ions to maintain a negative electric potential of approximately $90 \mathrm{mV}$ in the myocyte (phase 4). Depolarization of the cardiac cell membrane is caused by the rapid opening of $\mathrm{Na}+$ channels and subsequent massive $\mathrm{Na}+$ influx (phase 0 ). This $\mathrm{Na}+$ influx causes the rapid upstroke of the cardiac action potential as it is conducted through the ventricles and is directly responsible for the QRS interval of the ECG. The peak of the action potential is marked by the closure of $\mathrm{Na}+$ channels and the activation of $\mathrm{K}+$ efflux channels (phase 1). Calcium $(\mathrm{Ca}++)$ influx then occurs, allowing for a plateau in the action potential (phase 2) and continued myocardial contraction. The cardiac cycle ends with closure of the $\mathrm{Ca}++$ channels and activation of $\mathrm{K}+$ efflux channels, causing the potential to again approach $-90 \mathrm{mV}$ (phase 3). It is this potassium efflux from the myocardial cell that is directly responsible for the QT interval on the ECG [3].

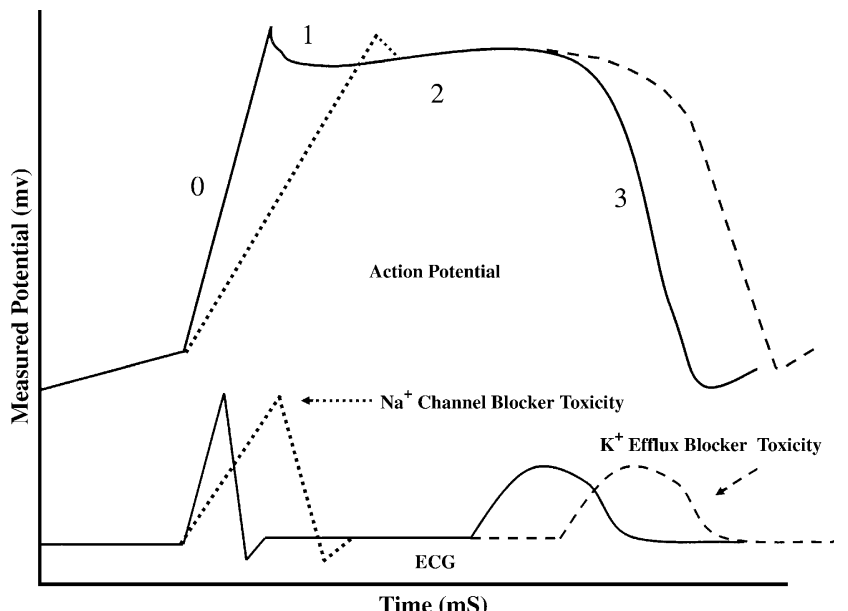

Fig. 1. Cardiac cycle action potential with corresponding electrocardiographic tracing. Dotted line indicates the changes associated with $\mathrm{Na}+$ channel blocker toxicity. Dashed line indicates the changes associated with $\mathrm{K}+$ efflux blocker toxicity. 


\section{Potassium efflux blocker toxicity}

\section{Background}

Medications in the $\mathrm{K}+$ efflux blocker category are listed in Table 1 . These medications all block the outward flow of potassium from intracellular to extracellular spaces. Myocardial repolarization is driven predominantly by this outward movement of potassium ions [3]. Blockade of the outward potassium currents by drugs may prolong the cardiac cycle action potential (Fig. 1) [4]. As a result, the primary electrocardiographic manifestation of potassium efflux blocker toxicity is QT interval prolongation. In fact, studies suggest that approximately $3 \%$ of total noncardiac prescriptions are associated with the potential for QT interval prolongation [5].

These medications vary in their propensity to induce QT interval prolongation or associated dysrhythmias at therapeutic and toxic levels. Some of these drugs, such as sotalol, are marketed specifically for their ability to inhibit this delayed rectifier current [6]. Other medications possess this activity as an unwelcome side effect at therapeutic doses. Several medications, such as terfenadine and cisapride, have been removed from the market in various countries because of reports of associated torsades de pointes and sudden death in patients taking these drugs [7,8]. Other medications in this class rarely have been reported to cause QT interval prolongation except when taken in massive overdose.

In addition, many of these drugs have other effects that can result in significant cardiovascular and electrocardiographic changes. For example, antipsychotic agents can cause muscarinic acetylcholine receptor and alpha-adrenergic receptor blockade and cardiac cell potassium, sodium, and calcium channel blockade.

\section{Electrocardiographic manifestations}

As noted, the primary electrocardiographic manifestation of $\mathrm{K}+$ efflux blocker toxicity is QT interval prolongation (Fig. 2). When measuring the QT interval, the ECG is best recorded at a paper speed of $50 \mathrm{~mm} / \mathrm{sec}$ and an amplitude of $0.5 \mathrm{mV} / \mathrm{cm}$ (the latter is equal to $20 \mathrm{~mm} / \mathrm{mV}$; the usual settings are $25 \mathrm{~mm} / \mathrm{sec}$ and $10 \mathrm{~mm} / \mathrm{mV}$ ). A tangent line then is drawn to the steepest part of the descending portion of the $T$ wave. The intercept between that line and the isoelectric line is defined as the end of the $\mathrm{T}$ wave. The QT interval then is measured from the beginning of the QRS complex to the end of the T wave. Within any ECG tracing, there is lead-to-lead variation of the QT interval. In general, the longest measurable QT interval on an ECG is regarded as determining the overall QT interval for a given tracing [9]. The QT interval is influenced by the patient's heart rate. The RR interval should be measured to allow for rate correction. Several formulas have been developed to correct the QT interval for the effect of heart rate (QTc), with Bazett's formula $\left(\mathrm{QTc}=\mathrm{QT} / \mathrm{RR}^{1 / 2}\right.$ ) being the most commonly 
Table 1

$\mathrm{K}^{+}$efflux channel blocking drugs

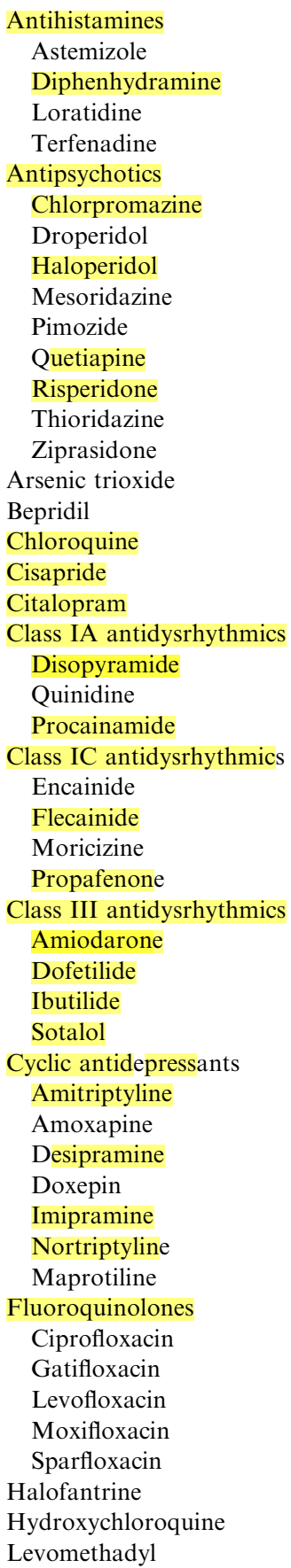


Table 1 (continued)

\author{
Macrolides \\ Clarithromycin \\ Erythromycin \\ Pentamidine \\ Quinine \\ Tacrolimus \\ Venlafaxine
}

used. QT interval prolongation is considered to occur when the QTc interval is greater than 0.44 seconds in men and 0.46 seconds in women.

The potential risk for QT interval prolongation with this class of medications is not simply related to a drug dose or concentration. Other factors also influence the QT interval, such as the patient's sex and electrolyte concentrations. In addition to QT interval prolongation, there is also the potential emergence of T- or U-wave abnormalities on the ECG with this class of medications [10].

Moreover, delay of repolarization causes the myocardial cell to have less charge difference across its membrane. This change can result in activation of the inward depolarization current (early after-depolarization), which may in turn promote triggered activity. This triggered activity potentially can progress to re-entry and subsequent polymorphic ventricular tachycardia, or torsades de pointes [11]. These dysrhythmias are associated most commonly with QT intervals greater than 0.50 seconds, although the potential for dysrhythmia for a given QT interval varies from drug to drug and patient to patient [3]. In addition, there is not a simple relationship between the degree of drug-induced QT interval prolongation and the potential for

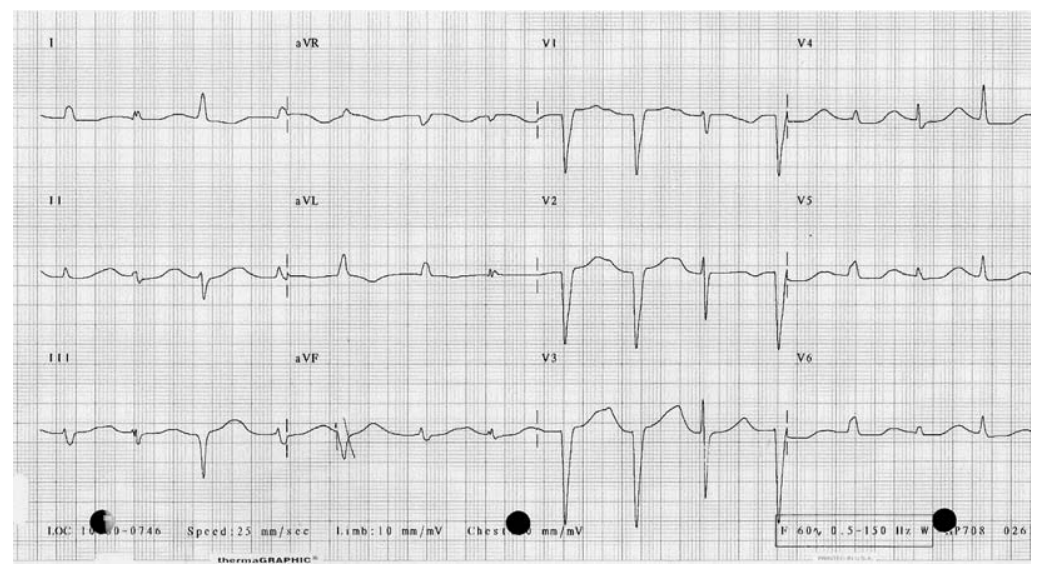

Fig. 2. $\mathrm{K}+$ efflux blocker toxicity. Note the marked QT interval prolongation on this 12-lead ECG; hydroxychloroquine was the offending agent. 
the occurrence of torsades de pointes. Drug-induced torsades de pointes can occur even without any substantial prolongation of the QT interval [3].

Similar to other members of this class, antipsychotic agents can cause significant QT interval prolongation and associated dysrhythmias. Additionally, other ECG abnormalities can be seen as a result of other actions of these agents. QRS complex widening can occur as a result of $\mathrm{Na}+$ channel blockade (see later discussion). Sinus tachycardia can occur because of the anticholinergic effect of these medications and from the reflex tachycardia induced by alpha-adrenergic blockade in the peripheral vasculature.

\section{Management}

If a patient has drug-induced QT interval prolongation, therapy should focus on immediate withdrawal of the potential cause and correction of any coexisting medical problems, such as electrolyte abnormalities. Patients who have newly diagnosed drug-induced prolongation of their QT interval should be considered candidates for admission to a monitored setting. Intravenous magnesium sulfate is a highly effective and benign intervention to suppress occurrence of dysrhythmias associated with QT interval prolongation, even though it typically does not result in shortening of the QT interval itself [12]. In patients who have intermittent runs of torsades de pointes not responsive to magnesium therapy, electrical overdrive pacing should be considered. In the presence of a non-perfusing rhythm, such as ventricular fibrillation, pulseless ventricular tachycardia, or torsades de pointes, unsynchronized electrical defibrillation should be performed.

\section{Sodium channel blocker toxicity}

\section{Background}

The ability of drugs to induce cardiac sodium $(\mathrm{Na}+)$ channel blockade has been well described in numerous literature reports [13]. This $\mathrm{Na}+$ channel blockade activity has been described as a membrane stabilizing effect, a local anesthetic effect, or a quinidine-like effect. Cardiac voltage-gated sodium channels reside in the cell membrane and open in response to depolarization of the cell (Fig. 1). The $\mathrm{Na}+$ channel blockers bind to the transmembrane $\mathrm{Na}+$ channels and decrease the number available for depolarization. This creates a delay of $\mathrm{Na}+$ entry into the cardiac myocyte during phase 0 of depolarization. As a result, the upslope of depolarization is slowed and the QRS complex widens. Myocardial $\mathrm{Na}+$ channel blocking drugs comprise a diverse group of pharmaceutical agents (Table 2). Specific drugs may affect not only the myocardial $\mathrm{Na}+$ channels, but also other myocardial ion channels, such as the calcium influx and potassium efflux. This may result in ECG changes and rhythm disturbances not related entirely to the drug's $\mathrm{Na}+$ channel blocking activity. For example, sodium 
Table 2

$\mathrm{Na}^{+}$channel blocking drugs

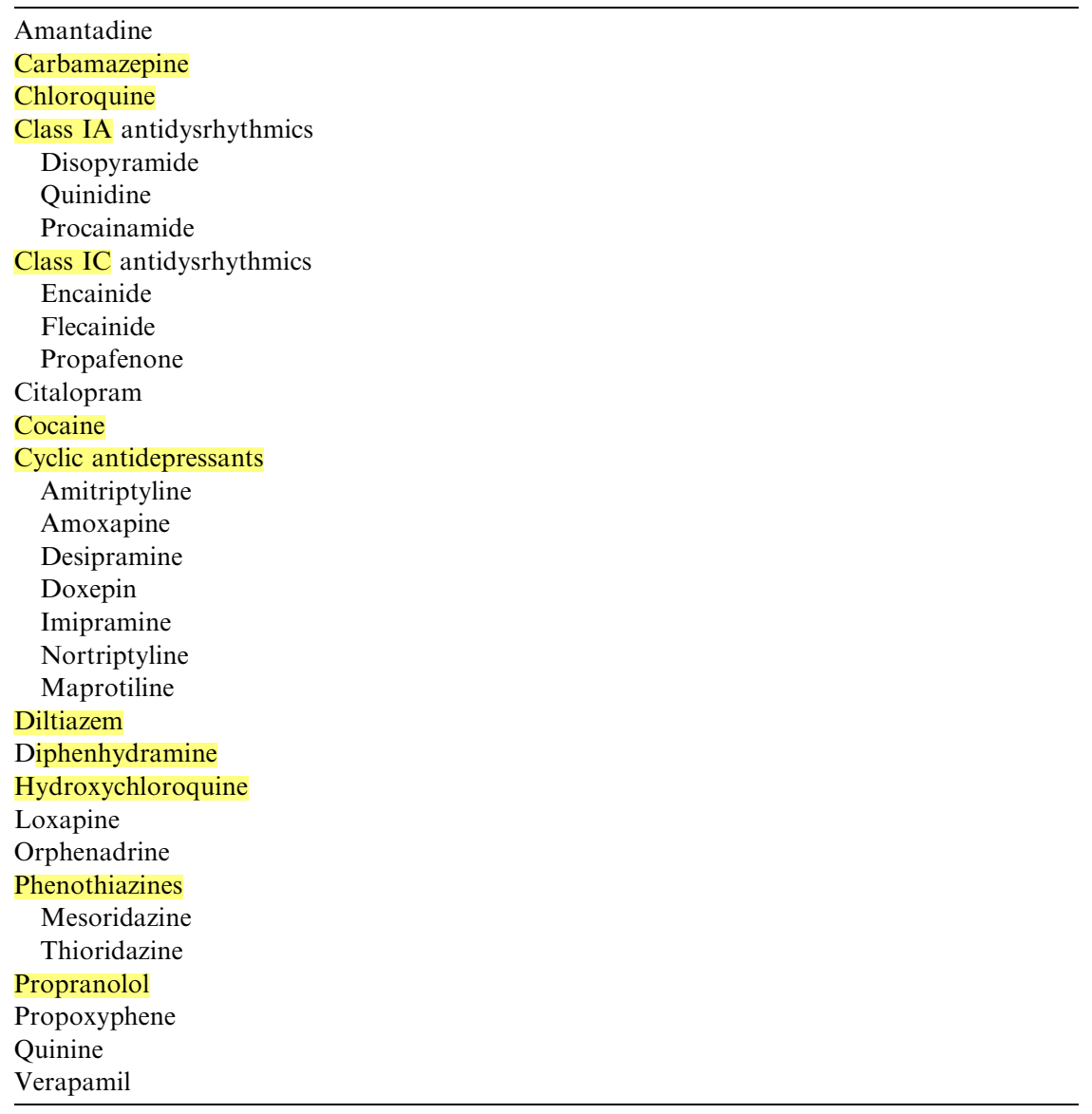

channel blocking medications such as diphenhydramine, propoxyphene, and cocaine also may develop anticholinergic, opioid, and sympathomimetic syndromes, respectively [14-16]. Similarly, cyclic antidepressant toxicity results not only from myocyte sodium channel blockade, but also from their action with respect to alpha-adrenergic blockade, muscarinic anticholinergic effects, and presynaptic neurotransmitter reuptake inhibition.

\section{Electrocardiographic manifestations}

As a result of its action in slowing the upslope of depolarization in the cardiac cycle, $\mathrm{Na}+$ channel blockers result in widening of the QRS complex (Fig. 3) [17]. In some cases, the QRS complexes may take the pattern of recognized bundle branch blocks $[18,19]$. In the most severe cases, the QRS prolongation becomes so profound that it is difficult to distinguish between 


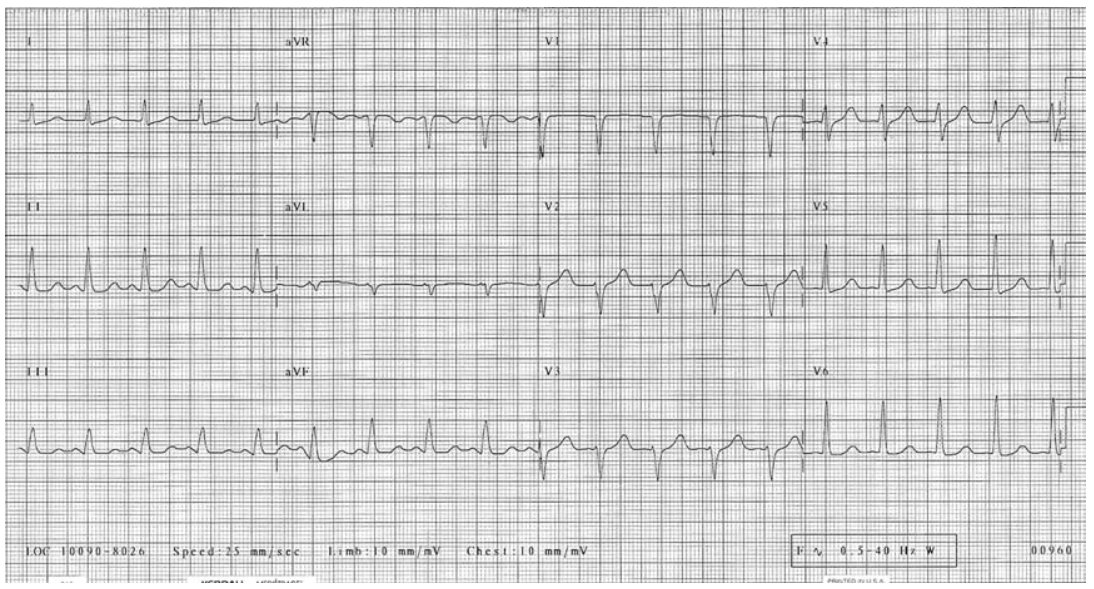

Fig. 3. Na + channel blocker poisoning. 12-lead ECG demonstrating QRS complex widening and tachycardia as a result of tricyclic antidepressant overdose.

ventricular and supraventricular rhythms [20,21]. Continued prolongation of the QRS complex may result in a sine wave pattern (Fig. 4) and eventual asystole.

Sodium channel blockers also may induce ventricular tachycardia [22]. It has been theorized that the $\mathrm{Na}+$ channel blockers can cause slowed intraventricular conduction, unidirectional block, the development of a reentrant circuit, and a resulting ventricular tachycardia (Fig. 5). These

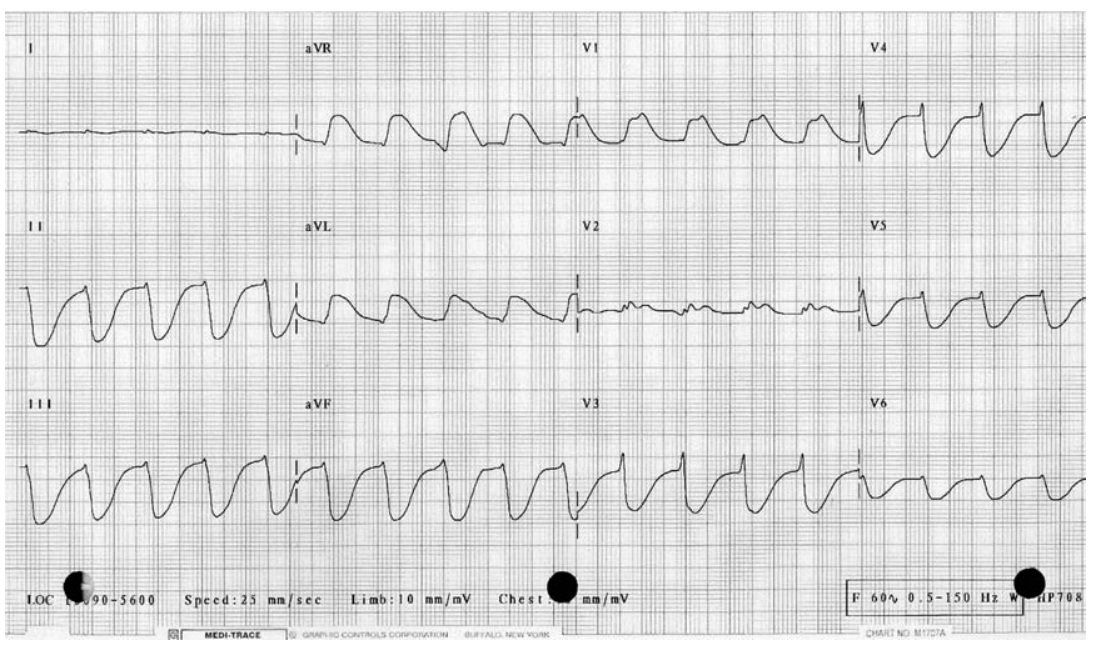

Fig. 4. Na+ channel blocking agent toxicity. 12-lead ECG demonstrating sine wave pattern following overdose; atrial and ventricular activity are difficult to distinguish. 


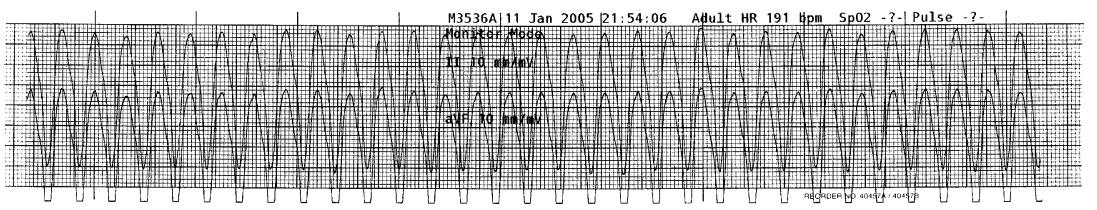

Fig. 5. Wide complex tachydysrhythmia caused by $\mathrm{Na}+$ channel blocker poisoning. ECG rhythm strip revealing a wide complex tachycardia following overdose of diphenhydramine.

rhythms then can degenerate into ventricular fibrillation. Because many of the $\mathrm{Na}+$ channel blocking agents are also anticholinergic or sympathomimetic agents, bradydysrhythmias are rare. The $\mathrm{Na}+$ channel blocking agents, however, can affect cardiac pacemaker cells. Bradycardia may occur because of slowed depolarization of pacemaker cells that depend on entry of sodium ions. In $\mathrm{Na}+$ channel blocker poisoning by anticholinergic and sympathomimetic drugs, the combination of a wide QRS complex and bradycardia is an ominous sign and may indicate that the $\mathrm{Na}+$ channel blockade is so profound that tachycardia does not occur, despite clinical muscarinic antagonism or adrenergic agonism [13].

In this class of agents, cyclic antidepressants produce several ECG changes related to $\mathrm{Na}+$ channel blockade and their other actions on cardiovascular function (see Fig. 3). Sinus tachycardia occurs frequently from the anticholinergic effects of cyclic antidepressant toxicity. QRS complex widening occurs as a result of $\mathrm{Na}+$ blockade, and this delayed conduction may be seen more commonly involving the right side of the heart, manifesting as a right bundle branch block [23]. In addition, QT interval prolongation can occur with these agents. Finally, rightward axis deviation of the terminal $40 \mathrm{msec}(0.04$ seconds) of the frontal plane QRS axis has been associated with tricyclic antidepressant poisoning [24,25]. The occurrence of this finding in other $\mathrm{Na}+$ channel blocking agents is unknown.

Cocaine is a unique sympathomimetic agent in its ability to cause cardiac $\mathrm{Na}+$ channel blockade. Together with QRS complex widening, increased catecholamine activity seen with cocaine toxicity can result in several rhythm disturbances, including sinus tachycardia, premature ventricular contractions, wide complex dysrhythmias, ventricular tachycardia, and ventricular fibrillation. In addition, morphologic changes in the ST segment and $\mathrm{T}$ waves consistent with ischemia can be seen in the setting of sympathomimetic and cocaine toxicity.

\section{Management}

The management of $\mathrm{Na}+$ channel blocking agents consists of administration of sodium or creation of an alkalosis [26-30]. Infusion of sodium bicarbonate by intermittent bolus or by continuous infusion has been advocated. Hypertonic sodium infusion and hyperventilation also have been advocated 
[31-34]. Reasonable, literature-supported indications for sodium bicarbonate infusion include a QRS duration of $>0.10$ seconds, persistent hypotension despite adequate hydration, and ventricular dysrhythmias. Lidocaine has been suggested in the treatment of ventricular dysrhythmias, though clear evidence is lacking. Class IA and IC antidysrhythmics should be avoided because of their ability to block cardiac sodium channels.

\title{
Sodium-potassium ATPase blocker toxicity
}

\section{Background}

Cardiac glycosides are agents that inhibit the sodium-potassium adenosine triphosphatase $(\mathrm{Na}+/ \mathrm{K}+$ ATPase $)$ pump. Digoxin and other digitalis derivatives are the cardiac glycosides encountered most widely, but numerous other similar acting agents also exist (Box 1). Digoxin historically has been administered to treat supraventricular tachydysrhythmias and congestive heart failure, but its use has been decreasing as newer agents have been developed. Nonprescription medication cardiac glycosides also have been associated with human toxicity, such as after ingestion of specific plants and contaminated herbal products [35-40].

The cardiac glycosides inhibit active transport of $\mathrm{Na}+$ and $\mathrm{K}+$ across cell membranes by inhibiting the $\mathrm{Na}+/ \mathrm{K}+$ ATPase. This results in an increase in extracellular $\mathrm{K}+$ and intracellular $\mathrm{Na}+$. An increased intracellular $\mathrm{Na}+$ reduces the transmembrane $\mathrm{Na}+$ gradient and subsequent increased activity of the $\mathrm{Na}+-\mathrm{Ca}^{2+}$ exchanger. This activity, in turn, increases the intracellular calcium concentration, which then augments myofibril activity in cardiac myocytes and results in a positive inotropic effect. The cardiac glycosides also increase vagal tone that may lead to a direct atrioventricular (AV) nodal depression. Therapeutically, digitalis derivatives are used to increase myocardial contractility or slow AV conduction. These actions, however, can result in significant cardiac disturbances and ECG abnormalities in the setting of toxicity.

\section{Box 1. Na+/K+ ATPase blocking agents and substances}

\author{
Bufadienolides \\ Digoxin \\ Digitoxin \\ Foxglove \\ Lily of the valley \\ Oleander \\ Red squill
}




\section{Electrocardiographic manifestations}

Digitalis derivatives at therapeutic doses have been associated with several electrocardiographic changes. These findings include the so-called "digitalis effect" manifesting with abnormal inverted or flattened T waves coupled with ST segment depression, frequently described as a sagging or scooped ST segment/T wave complex. These findings are most pronounced in leads with tall $\mathrm{R}$ waves. In addition, other findings include QT interval shortening as a result of decreased ventricular repolarization time, PR interval lengthening as a result of increased vagal activity, and increased U-wave amplitude. It is important to remember that these electrocardiographic manifestations are seen with therapeutic digoxin levels and do not correlate with toxicity.

Electrocardiographic abnormalities with cardiac glycoside toxicity are the result of the propensity for increased automaticity (from increased intracellular calcium) accompanied by slowed conduction through the AV node. As a result, cardiac glycoside toxicity may result in a wide array of dysrhythmias $[41,42]$. Excitant activity (atrial, junctional, and ventricular premature beats, tachydysrhythmias, and triggered dysrhythmias), suppressant activity (sinus bradycardia, bundle branch blocks, first-, second-, and third-degree AV blocks), and any combination of excitant and suppressant activity (atrial tachycardia with AV block, second-degree AV block with junctional premature beats) have all been reported (Fig. 6) [43-45].

The most common dysrhythmia associated with toxicity induced by these agents is frequent premature ventricular beats [42]. Paroxysmal atrial tachycardia with variable block or accelerated junctional rhythm is highly suggestive of digitalis toxicity. Marked slowing of the ventricular response in a patient who has atrial fibrillation who is on digoxin should suggest the possibility of toxicity (Fig. 6). Bidirectional ventricular tachycardia is stated to be specific for digitalis toxicity, but rarely is seen [46].

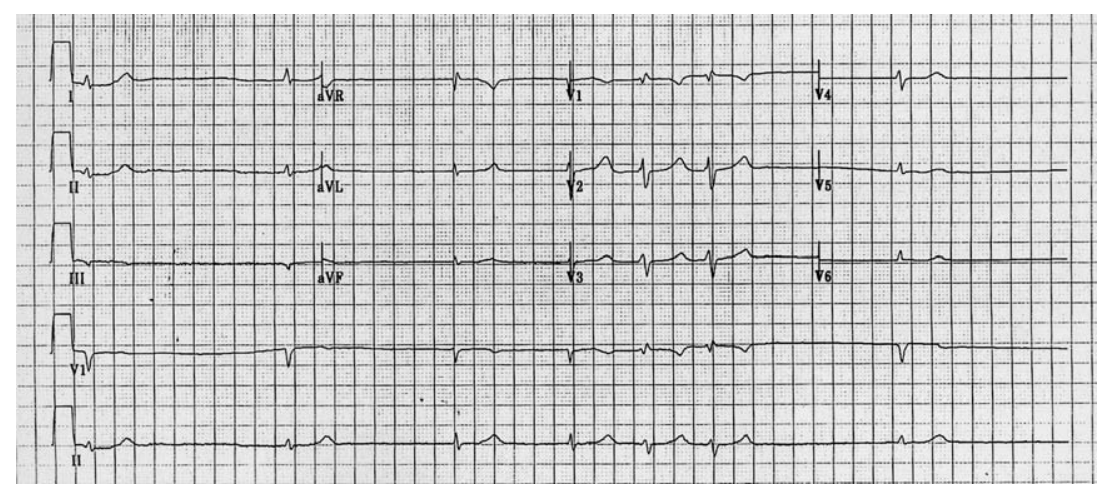

Fig. 6. $\mathrm{Na}+/ \mathrm{K}+$ ATPase blocker toxicity. 12-lead ECG demonstrating an irregular bradydysrhythmia as a result of conduction block from chronic digoxin toxicity. 
The ECG may demonstrate findings associated not only with cardiac glycoside toxicity but also with hyperkalemia. Acute toxicity most closely correlates with hyperkalemia as the $\mathrm{Na}+/ \mathrm{K}+$ ATPase is inhibited and extracellular $\mathrm{K}+$ increases. In chronic toxicity, hyperkalemia may not be seen because of the slower increase in $\mathrm{K}+$, allowing for renal compensation.

\title{
Management
}

In cardiac glycoside toxicity, digoxin-specific antibody (Fab) fragments are the first-line therapy in patients who have symptomatic cardiac dysrhythmias $[41,47]$. Because cardiac glycoside-enhanced vagal activity may be reversed by atropine sulfate, this agent has been used successfully in patients exhibiting AV block on ECG [48]. Cardiac pacing has been advocated for bradydysrhythmias unresponsive to atropine, but care should be exercised as the pacing wire itself may induce ventricular fibrillation [49]. The classic antidysrhythmic of choice for ventricular dysrhythmias is phenytoin, because it increases the ventricular fibrillation threshold in the myocardium and enhances conduction through the AV node [41]. Quinidine and procainamide are contraindicated because they depress AV nodal conduction and may worsen cardiac toxicity [50].

\section{Calcium channel blocker toxicity}

Background

There are currently nine cardiac calcium channel blockers (CCBs) that have been approved for clinical use in the United States. These nine are subclassified within four classes of compounds (Box 2). Over the past decade,

\author{
Box 2. $\mathrm{Ca}^{++}$channel blocking drugs \\ Dihydropyridines \\ Nicardipine \\ Nifedipine \\ Isradipine \\ Amlodipine \\ Felodipine \\ Nimodipine \\ Phenylalkylamine \\ Verapamil \\ Benzothiazepine \\ Diltiazem \\ Diarylaminopropylamine ether \\ Bepridil
}


the number of exposures to these agents has increased dramatically as they have become available on the market. In 2001, CCBs accounted for $40 \%$ of all the deaths caused by cardiovascular drugs reported to the AAPCC [51].

All cardiac CCBs inhibit the voltage sensitive L-type calcium channel within the cell membrane [52]. This channel resides in heart and smooth muscle cell membranes. The inhibition of this channel prevents movement of calcium from extracellular sites through the cell membrane to intracellular sites. Decreased intracellular calcium within the myocardial cells results in slowing of conduction, decreased contractility, and decreased cardiac output.

Blockade of calcium influx within the vascular smooth muscle cells results in vasodilation. Decreased cardiac output coupled with vasodilation can result in profound hypotension. The dihydropyridine class of drugs tends to have a higher affinity for the peripheral vascular smooth muscle cells, less effect on the cardiac calcium channels, and is associated more often with hypotension with a resulting reflex tachycardia. Verapamil and diltiazem, on the other hand, have strong affinity for cardiac and vascular calcium channels and subsequently the combination of hypotension with bradycardia may be seen. In animal models and human case series, CCBs also have been associated with cardiac sodium channel blockade [53,54].

\section{Electrocardiographic manifestations}

The inhibition of calcium influx within the conduction system results in slowing of cardiac conduction. CCB toxicity initially causes a sinus bradycardia that may or may not be symptomatic. Depending on the agent ingested, reflex tachycardia may not be seen. As levels of CCB increase, the patient may develop various degrees of AV block (first-, second-, and third-degree) and junctional and ventricular bradydysrhythmias on ECG (Fig. 7). A widening of the QRS complex may be encountered. This may be caused by ventricular escape rhythms or by CCB-induced sodium channel blockade causing a delay of phase 0 of depolarization. This delay and subsequent QRS complex widening also increases the potential for dysrhythmias (see the previous section on Sodium channel blocker toxicity)

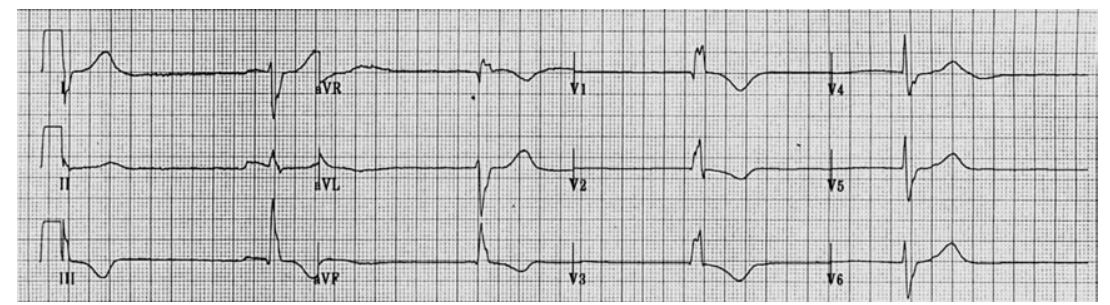

Fig. 7. CCB toxicity. 12-lead ECG demonstrating a marked bradydysrhythmia with a heart rate in the thirties. 
$[53,54]$. In the final stages, asystole may occur. Sudden shifts from bradydysrhythmias to cardiac arrest have been reported [53]. In addition, ECG changes associated with cardiac ischemia may occur as a result of the hypotension and changes in cardiovascular status, particularly in patients who have pre-existing cardiac disease.

\section{Management}

A symptomatic acute $\mathrm{CCB}$ overdose can be one of the most challenging poisonings encountered by a physician. $\mathrm{CCB}$ poisonings are prone to developing severe bradydysrhythmias and hypotension and other complications, including pulmonary edema and heart failure [55]. Specific pharmacologic therapy includes the use of atropine, calcium, glucagon, insulin, sodium bicarbonate, or various catecholamines [56,57].

\section{Beta-adrenergic blocker toxicity}

\section{Background}

BBs are used increasingly because of their efficacy in the treatment of hypertension, ischemic heart disease, and dysrhythmias. BBs competitively inhibit various $\beta$-adrenergic receptors. Inhibition of $\beta_{1}$-receptors results in a decrease in the force and rate of myocardial contraction, a decrease in $\mathrm{AV}$ nodal conduction velocity, and a decrease in renin secretion. Inhibition of $\beta_{2}$-receptors results in a decrease in glycogenolysis, decrease in gluconeogenesis, and decrease in relaxation of smooth muscles in blood vessels, bronchi, and the gastrointestinal tract. There are currently numerous BBs available (Box 3). These agents share in common the mechanism of

\section{Box 3. Beta-adrenergic blocking drugs}
Acebutolol
Atenolol
Betaxolol
Bisoprolol
Carvedilol
Esmolol
Labetalol
Metoprolol
Nadolol
Pindolol
Propranolol
Sotalol
Timolol 
competitive $\beta$-adrenergic receptor antagonism. Some of these agents have equal affinity for $\beta_{1}$ and $\beta_{2}$ receptors (eg, propranolol), whereas others are selective and have greater $\beta_{1}$ than $\beta_{2}$ receptor blocking activity (eg, metoprolol). Some agents also block other receptors, such as $\alpha$-adrenergic receptors (eg, labetalol), cardiac sodium channels (eg, propranolol, acebutolol), and cardiac potassium efflux channels (eg, sotalol) [58,59].

\section{Electrocardiographic manifestations}

In acute overdose, the most pronounced effects of BBs are on the cardiovascular system [60]. Bradycardia (from decreased sinoatrial node function), varying degrees of AV block, and hypotension are generally the hallmarks of significant beta-blocker toxicity. One prospective study attempted to characterize electrocardiographic findings in symptomatic BB overdose [61]. Only 3 of 13 symptomatic patients had bradycardia on their initial ECG (performed while they were classified as symptomatic). First-degree AV block was common, however. In fact, 10 of 12 symptomatic patients with a measurable PR interval (the thirteenth patient had atrial fibrillation) demonstrated a first-degree AV block and had a mean PR interval of 0.22 seconds. This finding was the most common abnormality to be found on electrocardiograms in this symptomatic patient group.

Besides bradycardia and AV block, there are other specific findings that can be seen with individual members within this group of medications. Propranolol is unique because of its $\mathrm{Na}+$ channel blocking activity in overdose that can result in a prolonged QRS interval ( $>0.10$ seconds) [58,61-63]. Propranolol overdose has been associated with a higher mortality rate compared with other BBs [66]. These same investigators also found that a QRS interval $>0.10$ seconds in these patients was predictive of propranololinduced seizures. Sotalol is a unique BB in that it possesses the ability to block delayed rectifier potassium channels in a dose-dependent fashion [64]. Acebutolol preferentially blocks $\beta_{1}$ receptors and possesses partial agonist activity and membrane stabilizing activity similar to propranolol. QRS interval widening on ECG and ventricular tachycardia have been reported in several cases $[59,65,66]$.

\section{Management}

Specific pharmacologic therapy for BB toxicity may include atropine, glucagon, calcium, insulin, or various catecholamines [67]. Atropine may be considered in an attempt to reverse bradycardia, but has been shown to have poor effect and no impact on blood pressure. Glucagon infusion, which increases intracellular cAMP, should be considered in symptomatic BB toxic patients [60]. Calcium has been shown to have efficacy at reversing the hypotensive effects of BB toxicity in animal models and human case reports $[60,68]$. Insulin infusions have been advocated for BB toxicity based on an 
animal model [69]. Catecholamine infusions may be considered after the therapies discussed previously fail to give adequate response. Pacemaker insertion, balloon pump, and bypass all may be considered in cases not responding to pharmacologic therapy.

\section{Summary}

Toxicologic, medication- and drug-induced changes and abnormalities on the 12-lead electrocardiogram (ECG) are common. A wide variety of electrocardiographic changes can be seen with cardiac and noncardiac agents and may occur at therapeutic or toxic drug levels. In many instances, however, a common mechanism affecting the cardiac cycle action potential underlies most of these electrocardiographic findings. Knowledge and understanding of these mechanisms and their related affect on the 12-lead ECG can assist the physician in determining those ECG abnormalities associated with specific toxidromes.

\section{References}

[1] Watson WA, Litovitz TL, Klein-Schwartz W, et al. 2003 annual report of the American Association of Poison Control Centers Toxic Exposure Surveillance System. Am J Emerg Med 2004;22(5):335-404.

[2] Albertson TE, Dawson A, de Latorre F, et al. TOX-ACLS: toxicologic-oriented advanced cardiac life support. Ann Emerg Med 2001;37(4 Suppl):S78-90.

[3] Yap YG, Camm AJ. Drug induced QT prolongation and torsades de pointes. Heart 2003; 89(11):1363-72.

[4] Anderson ME, Al-Khatib SM, Roden DM, et al. Cardiac repolarization: current knowledge, critical gaps, and new approaches to drug development and patient management. Am Heart J 2002;144(5):769-81.

[5] De Ponti F, Poluzzi E, Montanaro N, et al. QTc and psychotropic drugs. Lancet 2000; 356(9223):75-6.

[6] Munro P, Graham C. Torsades de pointes. Emerg Med J 2002;19(5):485-6.

[7] Kyrmizakis DE, Chimona TS, Kanoupakis EM, et al. QT prolongation and torsades de pointes associated with concurrent use of cisapride and erythromycin. Am J Otolaryngol 2002;23(5):303-7.

[8] Horowitz BZ, Bizovi K, Moreno R. Droperidol-behind the black box warning. Acad Emerg Med 2002;9(6):615-8.

[9] Chan T, Brady W, Harrigan R, et al, eds. ECG in emergency medicine and acute care. Philadelphia: Elsevier-Mosby; 2005.

[10] Sides GD. QT interval prolongation as a biomarker for torsades de pointes and sudden death in drug development. Dis Markers 2002;18(2):57-62.

[11] Nelson LS. Toxicologic myocardial sensitization. J Toxicol Clin Toxicol 2002;40(7):867-79.

[12] Kaye P, O'Sullivan I. The role of magnesium in the emergency department. Emerg Med J 2002;19(4):288-91.

[13] Kolecki PF, Curry SC. Poisoning by sodium channel blocking agents. Crit Care Clin 1997; 13(4):829-48.

[14] Zareba W, Moss AJ, Rosero SZ, et al. Electrocardiographic findings in patients with diphenhydramine overdose. Am J Cardiol 1997;80(9):1168-73. 
[15] Stork CM, Redd JT, Fine K, et al. Propoxyphene-induced wide QRS complex dysrhythmia responsive to sodium bicarbonate-a case report. J Toxicol Clin Toxicol 1995;33(2): $179-83$.

[16] Kerns W II, Garvey L, Owens J. Cocaine-induced wide complex dysrhythmia. J Emerg Med 1997;15(3):321-9.

[17] Harrigan RA, Brady WJ. ECG abnormalities in tricyclic antidepressant ingestion. Am J Emerg Med 1999;17(4):387-93.

[18] Heaney RM. Left bundle branch block associated with propoxyphene hydrochloride poisoning. Ann Emerg Med 1983;12(12):780-2.

[19] Fernandez-Quero L, Riesgo MJ, Agusti S, et al. Left anterior hemiblock, complete right bundle branch block and sinus tachycardia in maprotiline poisoning. Intensive Care Med 1985; 11(4):220-2.

[20] Brady WJ, Skiles J. Wide QRS complex tachycardia: ECG differential diagnosis. Am J Emerg Med 1999;17(4):376-81.

[21] Clark RF, Vance MV. Massive diphenhydramine poisoning resulting in a wide-complex tachycardia: successful treatment with sodium bicarbonate. Ann Emerg Med 1992;21(3): $318-21$.

[22] Joshi AK, Sljapic T, Borghei H, et al. Case of polymorphic ventricular tachycardia in diphenhydramine poisoning. J Cardiovasc Electrophysiol 2004;15(5):591-3.

[23] Liebelt EL, Francis PD, Woolf AD. ECG lead in aVR versus QRS interval in predicting seizures and arrhythmias in acute tricyclic antidepressant toxicity. Ann Emerg Med 1995;26: 195-201.

[24] Wolfe TR, Caravati EM, Rollins DE. Terminal 40-ms frontal plane QRS axis as a marker for tricyclic antidepressant overdose. Ann Emerg Med 1989;18(4):348-51.

[25] Berkovitch M, Matsui D, Fogelman R, et al. Assessment of the terminal 40-millisecond QRS vector in children with a history of tricyclic antidepressant ingestion. Pediatr Emerg Care 1995;11(2):75-7.

[26] Kerr GW, McGuffie AC, Wilkie S. Tricyclic antidepressant overdose: a review. Emerg Med J 2001;18(4):236-41.

[27] Wilson LD, Shelat C. Electrophysiologic and hemodynamic effects of sodium bicarbonate in a canine model of severe cocaine intoxication. J Toxicol Clin Toxicol 2003;41(6):777-88.

[28] Sharma AN, Hexdall AH, Chang EK, et al. Diphenhydramine-induced wide complex dysrhythmia responds to treatment with sodium bicarbonate. Am J Emerg Med 2003;21(3): $212-5$.

[29] Bou-Abboud E, Nattel S. Relative role of alkalosis and sodium ions in reversal of class I antiarrhythmic drug-induced sodium channel blockade by sodium bicarbonate. Circulation 1996;94(8):1954-61.

[30] Beckman KJ, Parker RB, Hariman RJ, et al. Hemodynamic and electrophysiological actions of cocaine. Effects of sodium bicarbonate as an antidote in dogs. Circulation 1991;83(5): 1799-807.

[31] McKinney PE, Rasmussen R. Reversal of severe tricyclic antidepressant-induced cardiotoxicity with intravenous hypertonic saline solution. Ann Emerg Med 2003;42(1):20-4.

[32] McCabe JL, Cobaugh DJ, Menegazzi JJ, et al. Experimental tricyclic antidepressant toxicity: a randomized, controlled comparison of hypertonic saline solution, sodium bicarbonate, and hyperventilation. Ann Emerg Med 1998;32(3 Pt 1):329-33.

[33] Hoffman JR, Votey SR, Bayer M, et al. Effect of hypertonic sodium bicarbonate in the treatment of moderate-to-severe cyclic antidepressant overdose. Am J Emerg Med 1993;11(4): $336-41$.

[34] Hoegholm A, Clementsen P. Hypertonic sodium chloride in severe antidepressant overdosage. J Toxicol Clin Toxicol 1991;29(2):297-8.

[35] Eddleston M, Ariaratnam CA, Sjostrom L, et al. Acute yellow oleander (Thevetia peruviana) poisoning: cardiac arrhythmias, electrolyte disturbances, and serum cardiac glycoside concentrations on presentation to hospital. Heart 2000;83(3):301-6. 
[36] Deaths associated with a purported aphrodisiac-New York City, February 1993-May 1995. MMWR Morb Mortal Wkly Rep 1995;44(46):853-5, 861.

[37] Gowda RM, Cohen RA, Khan IA. Toad venom poisoning: resemblance to digoxin toxicity and therapeutic implications. Heart 2003;89(4):e14.

[38] Gupta A, Joshi P, Jortani SA, et al. A case of nondigitalis cardiac glycoside toxicity. Ther Drug Monit 1997;19(6):711-4.

[39] Maringhini G, Notaro L, Barberi O, et al. Cardiovascular glycoside-like intoxication following ingestion of Thevetia nereifolia/peruviana seeds: a case report. Ital Heart J 2002;3(2): $137-40$.

[40] Scheinost ME. Digoxin toxicity in a 26-year-old woman taking an herbal dietary supplement. J Am Osteopath Assoc 2001;101(8):444-6.

[41] Irwin J. Intensive care medicine. In: Kirk M, Judge B, editors. Digitalis poisoning. 5th edition. Baltimore: Lippincott Williams \& Wilkins; 2003.

[42] Ma G, Brady WJ, Pollack M, et al. Electrocardiographic manifestations: digitalis toxicity. J Emerg Med 2001;20(2):145-52.

[43] Chen JY, Liu PY, Chen JH, et al. Safety of transvenous temporary cardiac pacing in patients with accidental digoxin overdose and symptomatic bradycardia. Cardiology 2004;102(3): $152-5$.

[44] Harrigan RA, Perron AD, Brady WJ. Atrioventricular dissociation. Am J Emerg Med 2001; 19(3):218-22.

[45] Behringer W, Sterz F, Domanovits H, et al. Percutaneous cardiopulmonary bypass for therapy resistant cardiac arrest from digoxin overdose. Resuscitation 1998;37(1):47-50.

[46] Lien WC, Huang $\mathrm{CH}$, Chen WJ. Bidirectional ventricular tachycardia resulting from digoxin and amiodarone treatment of rapid atrial fibrillation. Am J Emerg Med 2004;22(3):235-6.

[47] Woolf AD, Wenger T, Smith TW, et al. The use of digoxin-specific Fab fragments for severe digitalis intoxication in children. N Engl J Med 1992;326(26):1739-44.

[48] Kaplanski J, Weinhouse E, Martin O. Modification of digoxin induced arrhythmogenicity in adult rats following atropine administration. Res Commun Chem Pathol Pharmacol 1983; 39(1):173-6.

[49] Cummins RO, Haulman J, Quan L, et al. Near-fatal yew berry intoxication treated with external cardiac pacing and digoxin-specific FAB antibody fragments. Ann Emerg Med 1990; 19(1):38-43.

[50] Mordel A, Halkin H, Zulty L, et al. Quinidine enhances digitalis toxicity at therapeutic serum digoxin levels. Clin Pharmacol Ther 1993;53(4):457-62.

[51] Litovitz TL, Klein-Schwartz W, Rodgers GC Jr, et al. 2001 annual report of the American Association of Poison Control Centers Toxic Exposure Surveillance System. Am J Emerg Med 2002;20(5):391-452.

[52] Goldfrank L Goldfrank's toxicologic emergencies. In: DeRoos F, editor. Calcium channel blockers. 7th edition. New York: McGraw-Hill; 2002.

[53] Holstege C, Kirk M, Furbee R. Wide complex dysrhythmia in calcium channel blocker overdose responsive to sodium bicarbonate therapy [abstract]. J Toxicol Clin Toxicol 1998;36(5): 509.

[54] Tanen DA, Ruha AM, Curry SC, et al. Hypertonic sodium bicarbonate is effective in the acute management of verapamil toxicity in a swine model. Ann Emerg Med 2000;36(6): $547-53$

[55] Sami-Karti S, Ulusoy H, Yandi M, et al. Non-cardiogenic pulmonary oedema in the course of verapamil intoxication. Emerg Med J 2002;19(5):458-9.

[56] Kline JA, Tomaszewski CA, Schroeder JD, et al. Insulin is a superior antidote for cardiovascular toxicity induced by verapamil in the anesthetized canine. J Pharmacol Exp Ther 1993; 267(2):744-50.

[57] Kline JA, Leonova E, Raymond RM. Beneficial myocardial metabolic effects of insulin during verapamil toxicity in the anesthetized canine. Crit Care Med 1995;23(7):1251-63. 
[58] Love JN, Howell JM, Newsome JT, et al. The effect of sodium bicarbonate on propranololinduced cardiovascular toxicity in a canine model. J Toxicol Clin Toxicol 2000;38(4):421-8.

[59] Donovan KD, Gerace RV, Dreyer JF. Acebutolol-induced ventricular tachycardia reversed with sodium bicarbonate. J Toxicol Clin Toxicol 1999;37(4):481-4.

[60] Snook CP, Sigvaldason K, Kristinsson J. Severe atenolol and diltiazem overdose. J Toxicol Clin Toxicol 2000;38(6):661-5.

[61] Love JN, Enlow B, Howell JM, et al. Electrocardiographic changes associated with betablocker toxicity. Ann Emerg Med 2002;40(6):603-10.

[62] Reith DM, Dawson AH, Epid D, et al. Relative toxicity of beta blockers in overdose. J Toxicol Clin Toxicol 1996;34(3):273-8.

[63] Buiumsohn A, Eisenberg ES, Jacob H, et al. Seizures and intraventricular conduction defect in propranolol poisoning. A report of two cases. Ann Intern Med 1979;91(6):860-2.

[64] Neuvonen PJ, Elonen E, Tarssanen L. Sotalol intoxication, two patients with concentrationeffect relationships. Acta Pharmacol Toxicol (Copenh) 1979;45(1):52-7.

[65] Sangster B, de Wildt D, van Dijk A, et al. A case of acebutolol intoxication. J Toxicol Clin Toxicol 1983;20(1):69-77.

[66] Long RR, Sargent JC, Hammer K. Paralytic shellfish poisoning: a case report and serial electrophysiologic observations. Neurology 1990;40(8):1310-2.

[67] Goldfrank L. Goldfrank's toxicologic emergencies. In: Brubacher J, editor. Beta-adrenergic blockers. 7th edition. New York: McGraw-Hill; 2002.

[68] Love JN, Hanfling D, Howell JM. Hemodynamic effects of calcium chloride in a canine model of acute propranolol intoxication. Ann Emerg Med 1996;28(1):1-6.

[69] Kearns W, Schroeder D, Williams C, et al. Insulin improves survival in a canine model of acute beta-blocker toxicity. Ann Emerg Med 1997;29(6):748-57. 